\title{
Understanding children's preference for park features that encourage physical activity: an adaptive choice based conjoint analysis
}

\author{
Jenny Veitch ${ }^{1,2^{*}} \mathbb{D}$, Kylie Ball ${ }^{1}$, Elise Rivera ${ }^{1}$, Venurs Loh' ${ }^{1}$, Benedicte Deforche ${ }^{3,4}$ and Anna Timperio ${ }^{1}$
}

\begin{abstract}
Background: Parks are a key setting for physical activity for children. However, little is known about which park features children prefer and which features are most likely to encourage them to be active in parks. This study examined the relative importance of park features among children for influencing their choice of park for engaging in parkbased physical activity.

Methods: Children ( $n=252 ; 8-12$ years, 42\% male) attending three primary schools in Melbourne, Australia completed a survey at school. They were required to complete a series of Adaptive Choice-Based Conjoint analysis tasks, with responses used to identify the part-worth utilities and relative importance scores of selected park features using Hierarchical Bayes analyses within Sawtooth Software.

Results: For the overall sample and both boys and girls, the most important driver of choice for a park that would encourage them to be active was presence of a flying fox (overall conjoint analysis relative importance score: 15.8\%; $95 \% \mathrm{Cl}=14.5,17.1)$, followed by a playground $(13.5 \% ; 95 \% \mathrm{Cl}=11.9,15.2)$. For the overall sample, trees for climbing had the third highest importance score $(10.2 \% ; 95 \% \mathrm{Cl}=8.9,11.6)$; however, swings had 3rd highest importance for girls $(11.1,95 \% \mathrm{Cl}=9.3,12.9)$ and an obstacle course/parkour area had the $3 \mathrm{rd}$ highest importance score for boys $(10.7,95 \% \mathrm{Cl}=9.0,12.4)$. For features with two levels, part-worth utility scores showed that the presence of a feature was always preferred over the absence of a feature. For features with multiple levels, long flying foxes, large adventure playgrounds, lots of trees for climbing, large round swings, large climbing equipment, and large grassy open space were the preferred levels.
\end{abstract}

Conclusion: To ensure parks appeal as a setting that encourages children to engage in physical activity, park planners and local authorities and organisations involved in park design should prioritise the inclusion of a long flying fox, large adventure playgrounds, lots of trees for climbing, large round swings and obstacle courses/parkour areas.

Keywords: Parks, Green spaces, Active, Children, Urban, Attributes, Preferences

\section{Introduction}

Global evidence affirms the importance of regular physical activity for children for better physical health, including cardiorespiratory fitness, bone development and improved weight status, as well as enhanced mental,

\footnotetext{
*Correspondence: jenny.veitch@deakin.edu.au

${ }^{2}$ Burwood, Australia

Full list of author information is available at the end of the article
}

social, and cognitive health [1-3]. Despite these benefits, the majority of children worldwide do not achieve the recommended daily $60 \mathrm{~min}$ of moderate-to vigorous-intensity physical activity (MVPA) [4]. Evidence has shown that children's low physical activity may track into adolescence and adulthood $[5,6]$, making physical activity promotion during childhood paramount for present and future health. original author(s) and the source, provide a link to the Creative Commons licence, and indicate if changes were made. The images or other third party material in this article are included in the article's Creative Commons licence, unless indicated otherwise in a credit line to the material. If material is not included in the article's Creative Commons licence and your intended use is not permitted by statutory regulation or exceeds the permitted use, you will need to obtain permission directly from the copyright holder. To view a copy of this licence, visit http://creativecommons.org/licenses/by/4.0/. The Creative Commons Public Domain Dedication waiver (http://creativeco mmons.org/publicdomain/zero/1.0/) applies to the data made available in this article, unless otherwise stated in a credit line to the data. 
Research has shown that time spent outdoors is positively associated with children's physical activity [7] and public parks have become well recognised as a key setting for facilitating physical activity in a natural outdoor environment [8]. Parks not only provide opportunities for social interaction, relaxation and contact with nature, but also offer a supportive environment through the provision of activity-conducive amenities, such as playgrounds for climbing and swinging [9], and grassy open space and sports features for active recreation [10]. In addition, parks are sometimes described as an antidote to counterbalance the technological saturation among children [11]. Further, research has demonstrated that exercise performed in nature (green exercise) may confer greater health benefits, such as reduced stress and improved emotional well-being and overall mental health [7], than activity in other urban settings [12].

Although the majority of children in Australia have access to a park near home [13], many parks are not often visited or well utilised by children $[14,15]$. The nature of children's physical activity whilst visiting parks has been shown to range from sitting/standing to more vigorous activities $[9,16-19]$, with higher intensity of physical activity observed when using sports courts, fields and playgrounds in contrast to lower intensity physical activity in shelters/picnic areas and water play areas $[18,20$, 21]. Additionally, gender differences have been observed regarding the types of activities performed in parks [22], with girls being more likely to walk/run, be sedentary and use playgrounds, and boys being more likely to play active games and use sports facilities [18, 23]. It may be that the varied park use observed among children and between boys and girls reflects different preferences for park features that encourage park-based physical activity.

It has been suggested that appealing park features may be more important for encouraging park visits than park proximity or accessibility among children. For example, a recent study in Melbourne found that parents are willing to visit parks located further from home if they are equipped with relevant features, such as sports courts and ovals [24]. Quantitative and qualitative research has shown that playgrounds, shade, greenery, active recreation facilities, sports features (e.g., courts, fields), natural and water features, trees for climbing, open space, and sports programs are important for facilitating youth physical activity [13, 25-30]. However, the relative importance of different park features for promoting children's physical activity remains unknown.

Choice-based conjoint analyses examine how people value different characteristics (e.g., park features) of a product (e.g., park) and identify which characteristics have the greatest influence on preference or choice. Among adolescents, the limited evidence available using conjoint analysis indicates that park maintenance and play and fitness equipment were most important for encouraging adolescents' park visitation and park-based physical activity [31, 32]. However, the park features that are important drivers of children's preferences may differ from those of adolescents [22], and to date no study has examined which park features are most important relative to other features, for influencing choice of parks for encouraging active park use among children. A potential long-term strategy for increasing physical activity is to create and refurbish parks with features most preferred by a range of different people, including children, to maximise active use of parks by everyone. This is especially critical when resources are scarce. This study used Adaptive Choice-Based Conjoint (ACBC) analysis to examine the relative importance of park features with respect to children's preference for a park that would encourage them to engage in physical activity and explored differences according to gender. ACBC analysis is a quantitative market research method that examines how much people value specified features and different aspects of the features (feature levels) when making choice-based decisions between two options with a combination of features and feature levels [33]. In this study, this technique was applied to selected park features (i.e., swings) and park feature levels (i.e., large round swings, group swings in a circle, traditional swings, no swings).

\section{Methods}

This research was part of a larger study (ProjectPARK) that examined park characteristics influencing park visitation, park-based physical activity and social interaction among children, adolescents, and older adults [34-38]. For this component of the study, children in grades 3-6 (8-12 years) attending primary schools in Melbourne, Australia completed a survey on iPads during school time between November and December 2019. The survey took 15-30 min to complete. ACBC analysis, using Sawtooth SSI Web Lighthouse Studio 9.8.0 (www.sawtoothso ftware.com.au), was used to identify the relative importance of selected park features for influencing choice of park for active park use. Approval to conduct the study was obtained from the Deakin University Human Ethics Advisory Group (94_2017) and the Department of Education and Training.

\section{Recruitment}

Four primary schools that participated in an earlier phase of this project [38] were re-contacted to confirm their participation in this study. Three of these four schools agreed to participate in this study, one from each socioeconomic status (SES) area (low, middle, and high) based on the Australian Bureau of Statistics Socio Economic 
Index for Areas (SEIFA) for postcode [39]. The principal or delegate from each school was asked to purposefully select grade 3-6 classes to avoid inclusion of children who had participated in the previous phase of the study [38]. Participating schools provided between four and seven classes. Plain language statements and parental consent forms were sent home with the students in selected classes ( $n=488$ students). Completed consent forms were returned by 281 students (63\%); 13 students were absent on the day of data collection, five students had incomplete ACBC data, and 11 students were excluded due to participation in the previous study, resulting in a final sample of 252. Participation rates for eligible students from low, middle, and high SES schools were 25\% $(n=62), 47 \%(n=118)$ and $29 \%(n=72)$, respectively.

Participants completed survey items, including age, sex, school year, dog ownership, number of days they were physically active for at least $60 \mathrm{~min}$ in in a typical week [40,41], and time taken to walk from home to the park they visited most often. They also responded to items relating to their usual park visitation over the past 3 months: frequency and duration of park visitation; activities engaged in and activity levels when visiting parks; accompaniment at the park; frequency of meeting or talking to people they already knew, and to people they did not know, when at the park; and mode of transport used to travel to the park (see Table 1 for response options). These items have been used in previous studies with children of this age [38].

In a previous phase of the ProjectPARK study [38], children $(n=274)$ rated images of 42 park features according to how likely it is that the features would encourage them to engage in park-based physical activity. The top ten rated features from that study (based on mean scores) were identified separately for both boys and girls equating to 11 features, as the features in the top ten varied by sex. Previous research among adolescents in Belgium showed that preference for park features can vary according to frequency of park visitation and engagement in physical activity [42], thus, we also calculated mean scores and rankings for each feature according to frequency of park visitation (i.e. visit $\geq$ once/week, visit $<$ once/week) and whether or not participants met physical activity recommendations (i.e., $\geq 60 \mathrm{mins} \mathrm{MVPA} /$ day, $<60 \mathrm{mins}$ MVPA/day) via self-reported days per week they performed at least $60 \mathrm{~min}$ MVPA/day. Two additional features were in the top ten when ratings were examined by these two sub-groups; large grassy open space was ranked 10th for those who reported visiting parks <once/ week, and sports walls were ranked 8th for those who did not meet physical activity recommendations (data not shown). This resulted in the inclusion of written descriptions for a total of 13 features (see Table 2). Printed handouts showing images of examples of these features were also available to students whilst they were completing the survey. Each feature was presented with two levels - present or absent (e.g., sports goals, no sports goals); or three or four levels - high-to-low sequence order (e.g., giant slides, medium slides, no slides).

A series of $\mathrm{ACBC}$ tasks were completed by all participants to identify preferences for features and feature levels for encouraging park-based physical activity. An $A C B C$ survey is interactive as tasks are customised in real time based on individual preferences reported as participants progress through the survey [43]. In the previous rating study features were examined independently or in isolation, whereas with $\mathrm{ACBC}$ the features are examined conjointly. ACBC surveys tend to be realistic of people's real life decision-making as they employ non-compensatory procedures [44]. Participants were required to complete each task before progressing to the next task. Firstly, respondents selected six features from the list of 13 that would be most likely to encourage them to be active in the park. If any of the six selected features had three or four levels, participants were required to select their most preferred level. For example, for the feature 'slides', participants were asked to select their preferred level: 'giant slides,' 'medium slides', or 'no slides'.

Respondents were then shown a series of six 'screening' questions where four parks were described; each park had a different combination of feature levels for the six selected features. For each park, participants were required to indicate if the park described 'would' or 'would not' encourage them to be active. Based on responses to these screening questions, the program identified if any particular feature levels were included in parks that were selected as 'not encouraging' them to be active. In those cases, participants were asked additional question(s) to indicate whether any of the identified feature levels would be 'totally unacceptable' and to select the one feature level that was most unacceptable. Similarly, when the program's algorithm detected that certain feature levels were consistently included, respondents were asked to select the feature level that a park 'must have' to encourage them to be active when at the park. These 'must have' and 'unacceptable' questions determined whether specific feature levels were non-compensatory for choice and ensured that remaining tasks included features levels that best met each individual's needs.

Participants were then shown a series of 13 'choice tasks' that included descriptions of two parks. They were asked to select the park that was most appealing for encouraging them to be active. Each park had a different combination of the levels of the six features that had been identified in the previous sections as 'possibilities' (i.e., 
Table 1 Demographic characteristics of participants $(n=252)$

\begin{tabular}{|c|c|}
\hline Age, mean years [SD] & $10.2[1.4]$ \\
\hline Sex, Male, n(\%) & $105(41.7)$ \\
\hline Dog owner, n(\%) & $85(33.7)$ \\
\hline \multicolumn{2}{|l|}{ School year level n(\%) } \\
\hline Year 3 & $85(34.1)$ \\
\hline Year 4 & $38(15.3)$ \\
\hline Year 5 & $28(11.2)$ \\
\hline Year 6 & $98(39.4)$ \\
\hline \multicolumn{2}{|l|}{ Usual frequency of park visit, n(\%) } \\
\hline$\geq$ once per week & $139(55.4)$ \\
\hline 2-3 times per month & $53(21.1)$ \\
\hline$\leq$ once per month & $41(16.3)$ \\
\hline Haven't visited a park in the past 3 months & $18(7.2)$ \\
\hline \multicolumn{2}{|l|}{ Usual duration of park visit, n(\%) } \\
\hline$<30$ mins & $19(7.6)$ \\
\hline $30 \mathrm{~min}$ to $1 \mathrm{~h}$ & $96(38.4)$ \\
\hline$>1$ to $<2 \mathrm{~h}$ & $62(24.8)$ \\
\hline 2 or more hours & $55(22.0)$ \\
\hline Haven't visited a park in the past 3 months & $18(7.2)$ \\
\hline \multicolumn{2}{|l|}{ Usual activity levels during park visit, n(\%) } \\
\hline Mostly sitting & $8(3.2)$ \\
\hline Mostly light activities & $22(8.9)$ \\
\hline Mostly moderate activities & $127(51.2)$ \\
\hline Mostly vigorous activities & $73(29.4)$ \\
\hline Haven't visited a park in the past 3 months & $18(7.3)$ \\
\hline \multicolumn{2}{|l|}{ Usual accompaniment to the park, $\mathrm{n}(\%)^{\mathrm{a}}$} \\
\hline No one (without dog) & $45(17.9)$ \\
\hline Parent & $166(65.9)$ \\
\hline Other adult & $64(25.4)$ \\
\hline Sibling(s) & $146(57.9)$ \\
\hline Friend(s) & $146(57.9)$ \\
\hline Organised Group & $47(18.7)$ \\
\hline $\operatorname{Dog}(s)$ & $58(23.0)$ \\
\hline Haven't visited a park in the past 3 months & $18(7.1)$ \\
\hline \multicolumn{2}{|l|}{ Usual activities performed, $\mathrm{n}(\%)^{\mathrm{a}}$} \\
\hline Walk & $80(31.7)$ \\
\hline Walk the dog & $63(25.0)$ \\
\hline Jog & $83(32.9)$ \\
\hline Ride bike/scooter/skateboard & $129(51.2)$ \\
\hline Ball games & $123(48.8)$ \\
\hline Play on playground & $161(63.9)$ \\
\hline Picnic/BBQ & $76(30.2)$ \\
\hline Watch sport & $35(13.9)$ \\
\hline Major event & $52(20.6)$ \\
\hline Hung out with family & $127(50.4)$ \\
\hline Hung out with friends & $154(61.1)$ \\
\hline Relaxed & $95(37.7)$ \\
\hline Café & $37(14.7)$ \\
\hline Geocaching/outdoor treasure hunt & $12(4.8)$ \\
\hline Virtual reality games & $17(6.7)$ \\
\hline Haven't visited a park in the past 3 months & $18(7.1)$ \\
\hline
\end{tabular}


Table 1 (continued)

\begin{tabular}{|c|c|}
\hline \multicolumn{2}{|c|}{ Usual mode of transport to park visited most often, $\mathrm{n}(\%)^{\mathrm{a}}$} \\
\hline Walk & $181(71.8)$ \\
\hline Jog & $62(24.6)$ \\
\hline Cycle & $105(41.7)$ \\
\hline Public Transport & $8(3.2)$ \\
\hline Car & $127(50.4)$ \\
\hline Haven't visited a park in the past 3 months & $18(7.1)$ \\
\hline \multicolumn{2}{|c|}{ Frequency of talking to people in park never met previously, n(\%) } \\
\hline Never/rarely & $137(54.4)$ \\
\hline Sometimes & $59(23.4)$ \\
\hline Most of the time/always & $38(15.1)$ \\
\hline Haven't visited a park in the past 3 months & $18(7.1)$ \\
\hline \multicolumn{2}{|c|}{ Frequency of talking to people in park that they already knew, n(\%) } \\
\hline Never/rarely & $120(47.6)$ \\
\hline Sometimes & $77(30.6)$ \\
\hline Most of the time/always & $37(14.7)$ \\
\hline Haven't visited a park in the past 3 months & $18(7.1)$ \\
\hline \multicolumn{2}{|c|}{ Number of days of $\geq 60$ mins physical activity per day in usual week, $n(\%)$} \\
\hline$<7$ days/week & $186(74.7)$ \\
\hline 7 days/week & $63(25.3)$ \\
\hline
\end{tabular}

${ }^{\mathrm{a}}$ Multiple responses allowed

feature levels had not been marked as 'unacceptable'). The "winning" park profile for each choice task tournament was included in the following rounds of the choice task tournament until the most preferred profile was determined [44]. Examples of each of the main tasks are included in Additional file 1. Pilot testing was performed with two girls and two boys aged 7-12 years, and minor amendments for clarity were made accordingly.

\section{Data analyses}

Descriptive characteristics of the sample were calculated using Stata version 15 (Stata Corp., College Station, TX, USA). Data from the ACBC survey were analysed using Sawtooth SSI Web Lighthouse Studio 9.8.0. ACBC analysis yield two types of parameters: part-worth utilities and average relative importance scores [43]. A part-worth utility represents the preference for a level within each feature, with a higher, positive value indicating a greater preference for that level. For example, if the feature levels 'giant slides', 'medium slides' and 'no slides' had part-worth utility values of 20,15 and -5 respectively, this means that 'giant slides' were the most preferred level and 'no slides' were the least preferred level. To assist with interpretation, part-worth utility scores were zero-centred by the software. A low, negative value for 'no slides' does not indicate that this level was disliked but rather that it was the least preferred of all the feature level options.
Part-worth utilities can only be compared within a given feature (i.e., cannot be compared to the preferred levels of other features).

Relative importance scores are presented as a percentage and represent which features have the greatest or least effect on choice, with greater importance scores reflecting greater effects on choice. Importance scores for a feature are the difference between the least and most favorable feature levels (i.e., range from the part-worth utility values for the levels for that feature). The importance scores are also ratio-scaled; for example, a feature with an importance score of $20 \%$ is twice as important as a feature with an importance score of $10 \%$.

Individual part-worth utility and importance scores were estimated for the overall sample and according to gender with Hierarchical Bayes (HB) analyses [45]. For each part-worth utility and importance score, standard deviations, standard errors and 95\% confidence intervals were calculated and presented graphically. Significant differences between levels of each feature (part-worth utilities) and different features (importance scores) were indicated by non-overlapping confidence intervals. The overall fit of a HB model was interpreted with Root LikeliHood (RLH) values ranging from zero to one, with a higher value indicating a better fit of the model. There were 40,000 iterations for the HB models, the recommended number for reaching successful convergence [43]. 
Table 2 Park features and feature levels

\begin{tabular}{|c|c|}
\hline Feature & Feature level \\
\hline \multirow[t]{3}{*}{ 1. Playground } & i. Large adventure playground \\
\hline & ii. Small playground \\
\hline & iii. No playground \\
\hline \multirow[t]{2}{*}{ 2. Obstacle course/parkour } & i. Obstacle/parkour course \\
\hline & ii. No obstacle/parkour course \\
\hline \multirow[t]{3}{*}{ 3. Slides } & i. Giant slides \\
\hline & ii. Medium slides \\
\hline & iii. No slide \\
\hline \multirow[t]{3}{*}{ 4. Flying fox } & i. Long flying fox \\
\hline & ii. Short flying fox \\
\hline & iii. No flying fox \\
\hline \multirow[t]{3}{*}{ 5. Climbing equipment } & i. Large climbing equipment \\
\hline & ii. Small to medium climbing equipment \\
\hline & iii. No climbing equipment \\
\hline \multirow[t]{2}{*}{ 6. Waterplay } & i. Waterplay area \\
\hline & ii. No waterplay area \\
\hline \multirow[t]{3}{*}{ 7. Trees for climbing } & i. Lots of trees for climbing \\
\hline & ii. Some trees for climbing \\
\hline & iii. No trees for climbing \\
\hline \multirow[t]{4}{*}{ 8. Swings } & i. Large round swings \\
\hline & ii. Group swings in a circle \\
\hline & iii. Traditional swings \\
\hline & iv. No swing \\
\hline \multirow[t]{2}{*}{ 9. Outdoor fitness equipment } & i. Outdoor fitness equipment \\
\hline & ii. No outdoor fitness equipment \\
\hline \multirow[t]{3}{*}{ 10. Grassy open space } & i. Large grassy open space \\
\hline & ii. Medium grassy open space \\
\hline & iii. Little to no grassy open space \\
\hline \multirow[t]{2}{*}{ 11. Interactive areas } & i. Interactive areas \\
\hline & ii. No interactive areas \\
\hline \multirow[t]{2}{*}{ 12. Sports goals } & i. Sports goals \\
\hline & ii. No sports goals \\
\hline \multirow[t]{2}{*}{ 13. Sports wall } & i. Sports wall \\
\hline & ii. No sports wall \\
\hline
\end{tabular}

\section{Results}

The demographic characteristics of the sample are presented in Table 1 . Children (42\% male) were spread across grades 3-6. More than $50 \%$ of participants reported visiting a park at least once per week, approximately $80 \%$ usually engaged in MVPA during their park visits, $66 \%$ were usually accompanied by a parent and $72 \%$ reported usually walking to the park they visited most often. More than half (54\%) of children never or rarely spoke to people they had never met previously and $48 \%$ never or rarely spoke with people they already knew $(48 \%)$ when in the park.

\section{Part-worth utilities}

The overall average utilities of the park features are presented in Fig. 1. For features with two levels, the presence of a feature was always preferred over the absence of a feature. For example, there was a higher preference for having a water play area $(32.5,95 \% \mathrm{CI}=26.8,38.2)$ than having no water play area $(-32.5,95 \% \mathrm{CI}=-38.2$, -26.8 ).

For features with three levels, the higher sequence order was always preferred. For example, having no climbing equipment had a significantly lower preference $(-58.2$, $95 \% \mathrm{CI}=-66.7,-49.7)$ than medium climbing equipment $(4.5,95 \% \mathrm{CI}=0.8,8.2)$, which again had a lower preference than large climbing equipment $(53.6,95 \% \mathrm{CI}=45.8$, 61.5). These findings were consistent for boys and girls. For swings, large round swings had the highest partworth utility score $(31.8,95 \% \mathrm{CI}=25.8,37.8)$ overall, followed by group swings in a circle $(18.3,95 \% \mathrm{CI}=12.7$, 23.9) and traditional swings $(15.4,95 \% \mathrm{CI}=9.8,21.0)$ which were not significantly different from each other, and then no swings $(-65.4,95 \% \mathrm{CI}=-74.9,-56.0)$. These findings were consistent for girls. However, for boys' preferences for large round swings $(23.94,95 \% \mathrm{CI}=13.7$, $34.2)$ and traditional swings $(22.54,95 \% \mathrm{CI}=12.1,33.0)$ were similar, with lower preference for group swings in a circle $(3.53,95 \% \mathrm{CI}=-2.1,9.1)$ and no swings $(-50.0$, $95 \% \mathrm{CI}=-62.9,-37.2)$.

\section{Relative importance scores}

Overall, the two most important park features influencing choice were a flying fox (e.g., zip line cable between two points) $(15.8 \%$; $95 \% \mathrm{CI}=14.5,17.1)$ and a playground $(13.5 \%$; $95 \% \mathrm{CI}=11.9,15.2)$, followed by trees for climbing $(10.2 \% ; 95 \% \mathrm{CI}=8.9,11.6)$ and swings $(9.2 \%$; $95 \% \mathrm{CI}=8.0,10.5)$ (Fig. 2). Interactive areas were the least important feature $(2.3 \% ; 95 \% \mathrm{CI}=1.6,2.9)$.

A few differences were observed by gender. Swings was third most important for girls $(11.09,95 \% \mathrm{CI}=9.3$, 12.9), whereas it was seventh most important for boys $(7.9,95 \% \mathrm{CI}=6.1,9.7)$. Water play areas was eighth most important for girls $(6.2,95 \% \mathrm{CI}=4.9,7.5)$ and the 11 th most important for boys $(3.8,95 \% \mathrm{CI}=2.5,5.0)$. Obstacle course/parkour areas was third most important for boys $(10.7,95 \% \mathrm{CI}=9.0,12.4)$ and sixth most important for girls $(7.5,95 \% \mathrm{CI}=6.6,8.7)$ and sports goals was sixth most important for boys $(8.3,95 \% \mathrm{CI}=6.2,10.3)$ and 11 th most important for girls $(2.8,95 \% \mathrm{CI}=1.7,3.9)$.

\section{Discussion}

This study used ACBC analyses to identify the relative importance of specific park features for influencing choice of park for encouraging physical activity among 


\section{$-150$}

$-100$

$-50$

50

100

150

Large adventure playground Small playground

No playground

Obstacle/parkour course No obstacle/parkour course

Giant slides

Medium slides

No slide

Long flying fox

Short flying fox

No flying fox

Large climbing equipment Small to medium climbing equipment

No climbing equipment

Waterplay area

No waterplay area

Lots of trees for climbing

Some trees for climbing

No trees for climbing

Large round swings

Group swings in circle

Traditional swings

No swings

Outdoor fitness equipment No outdoor fitness equipment

Large grassy open space

Medium grassy open space Little to no grassy open space

Sports wall

No sports wall

Interactive areas

No interactive areas

Sports goals

No sports goals

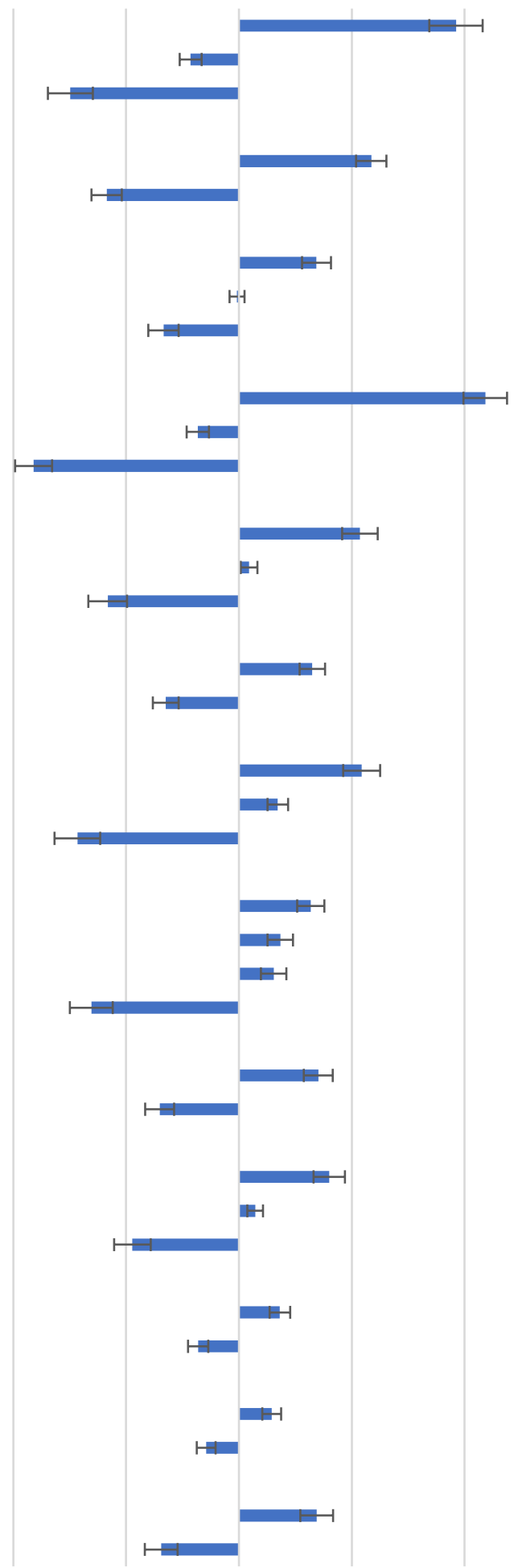

Fig. 1 Overall average utilities for park features encouraging physical activity 


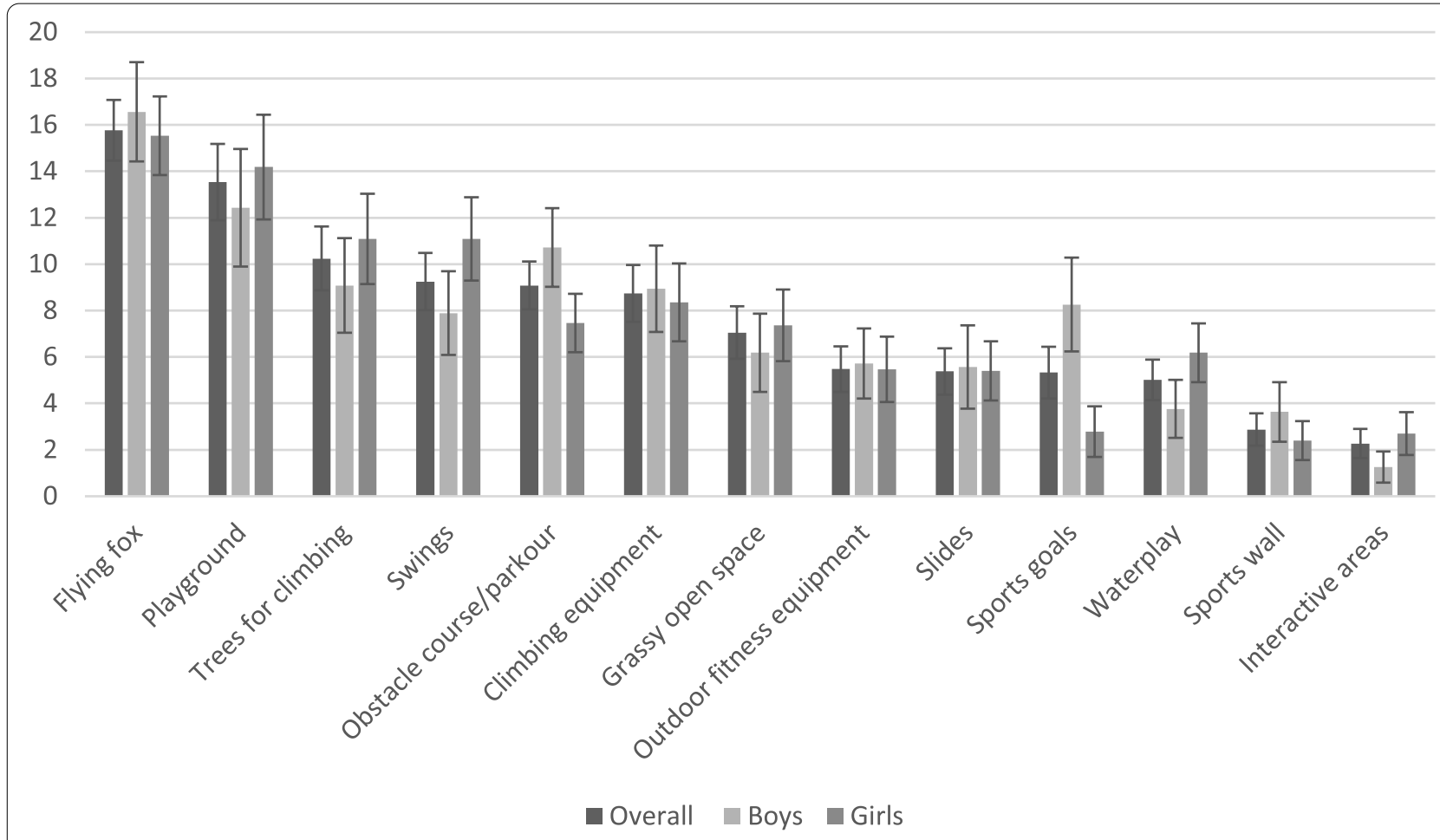

Fig. 2 Relative importance scores for encouraging physical activity among children

children. In general, for every feature examined, children preferred the existence of a feature over the absence of a feature, and they preferred the bigger or more challenging level described. For example, a long flying fox was preferred over a short flying fox. Overall, across all features in the 'tournament', the three features that were the most important driver of choice for a park that would encourage them to be active were a flying fox, a playground, and trees for climbing. For girls, however, swings had the third highest importance score and for boys an obstacle course/parkour area had the third highest importance score. Therefore, to cater for both boys and girls, long flying foxes, a large adventure playground, lots of trees for climbing, large swings, and obstacle course/ parkour areas should also be prioritised to encourage active park use.

Overall, our findings suggest that parks equipped with a diversity of play elements are more likely to appeal to children as a park that would encourage them to engage in park-based physical activity. This supports research from the US that found that the more play elements present in a playground, the more visitors of all ages visited the playground and engaged in park-based physical activity [46]. When planning the playground equipment, it is critical to consider the type of equipment. For example, for both the overall sample and boys and girls, large round swings had the highest part-worth utility scores and therefore, planners should consider the specific type of swing that is installed. Children also appeared to consistently prefer feature levels with the highest level of physical challenge (e.g., long flying fox, large adventure playground, large round swings). This is consistent with previous research that highlighted children's preference for physical challenge during park play [30, 36]. For example, in a recent qualitative study, children stated that the park features they liked the most were the play elements with risk and challenge and the park features they disliked were the elements that were too small or 'boring' [36]. Previous research has also identified that elements of physical challenge are necessary to stimulate and support park-based physical activity among adolescents [31, 35]. A systematic review also found 'risky' outdoor play to be positively associated with a variety of health behaviours among children [47]. When planning and renewing parks, stakeholders should give careful consideration to equipping parks and playgrounds with elements that are challenging and adventurous to support physical activity among youth.

It is unsurprising that sports goals were of higher importance for boys (6th) than for girls (11th), as boys are more likely to play team sports such as soccer or basketball and girls are more likely to participate in less team orientated activities such as dancing and gymnastics [48]. Previous research has also highlighted boys' 
preference for sports-related activities [18, 23]. Obstacle course/parkour areas also had a higher importance score for boys (3rd) than for girls (6th), although this feature had the fifth highest importance score overall. Obstacle courses/parkour equipment is relatively new in parks in Australia and further research is required to understand specific details on the type of obstacle/parkour equipment that may promote sustained and active use among children.

For the overall sample, water play areas, sports walls and interactive areas had the three lowest importance scores of the 13 features examined in this sample of children. This was generally consistent for both boys and girls; however, water play areas had a higher importance score (8th) among girls than boys (11th). This does not mean that these features are not important; it just shows that of the 13 included features that they had the lowest importance. However, previous research has reported lower physical activity levels among children using water play areas compared to playground areas [21]. Interestingly, in our previous research, children ranked interactive areas highly for encouraging visitation and park-based social interaction [38]. Therefore, although in the present study they were not found to be as important as other features for driving choice for a park that would encourage physical activity, interactive areas may support and promote park visitation but not necessarily physical activity. These types of digital installations are a relatively new feature in parks, so future research is necessary to explore the types of equipment that may be most appealing for children as well as other population groups.

Our findings highlight the need to consider the specific needs of children, and the differential needs of boys and girls, when designing parks as their preferences are different to those of older adults (under review) and adolescents (under review). For example, two studies that also used ACBC analysis found the three most important drivers of preference for parks that would encourage park-based physical activity among adolescents were the presence of sports courts, grassy open space, and outdoor fitness equipment (under review) and among older adults were walking paths, shady trees, and a peaceful and relaxed setting (under review). This confirms the need to consider all age groups when planning parks; as well as inter-generational needs, as previous research has shown that a large percentage of older adults visit parks with their grandchildren [37].

\section{Strengths and limitations}

To our knowledge, this is the first study to use ACBC analysis to examine this research question among children. Obtaining input from children directly is critical to ensure that park design meets their specific needs and analysis by gender made it possible to determine if preferences for particular features were more or less important for boys and girls. However, it is important to acknowledge the following limitations and considerations. The selected features were based on results from walk-along interviews in urban parks with children [36] and children's ratings of digital images [38]; however, it is possible that other park features may be more/less important than the features included. The inclusion of children attending schools located in low, mid and high SES areas, who were both regular and irregular park users, are further strengths of this study as it enabled us to obtain information from participants living in neighbourhoods with diverse socio-demographic characteristics and with varied park experiences. Future studies should consider including children living in non-urban areas as park features have been shown to differ in urban versus rural parks [49], and children in rural areas may have different preferences. Future studies may also wish to examine preferences according to individual level SES. Most children in the current study reported visiting a park at least once per week (55\%) and (80\%) reported usually engaging in MVPA during their park visits, so it would also be valuable for future research to identify if specific park features would encourage children who visit less regularly or who are usually less active during their park visits to be more active when at the park. Although challenging [46], ideally future research should also seek opportunities for natural experimental studies to examine the impact of incorporating these findings in park design and examining the impact of these changes on children's park-use behaviour.

The methodology employed is a novel approach to obtaining information about drivers of preference for park features over a series of choice tasks. While ACBC survey tasks can be considered complex, the in-class methodology with research supervision helped to ensure successful completion with children 8-12years as they could ask questions and receive assistance at the time of completing the survey. Features were described with a written description, which is consistent with previous conjoint analysis studies [31, 50]; however, it is possible that the children may have had varied interpretations of the written descriptions. To help minimise this potential limitation, examples of the features presented in the $\mathrm{ACBC}$ survey were presented as images on handouts during survey completion. Future studies may consider the use of images of park features within the ACBC survey. Finally, the focus of this study was on in-park features. Future studies should also examine the relative importance of other factors external to the park that influence park visits, such as proximity to home, accessibility, and transportation. 


\section{Conclusion}

This study provides much-needed practical evidence and insights to inform the planning and design of future parks (re)developments to support active park use among children based on their preferences. To ensure parks are appealing as a setting that encourages children to engage in physical activity during their park visits, the findings from this study suggest that policymakers should prioritise the inclusion of a long flying fox, large adventure playgrounds, lots of trees for climbing, large round swings, obstacle courses/parkour areas and large climbing equipment. The next step is to examine the impact of incorporating these findings in park design and examining the impact of these changes on children's park-use behaviour [39]. Future planning decisions should consider park feature preferences as well as other factors that impact park use such as accessibility, and availability.

\section{Supplementary Information}

The online version contains supplementary material available at https://doi. org/10.1186/s12966-021-01203-X.

Additional file 1. Examples of Adaptive Choice Based Conjoint Analysis survey questions.

\section{Acknowledgements}

The authors gratefully acknowledge the participants in this study and all research staff involved in ProjectPARK.

\section{Authors' contributions}

JV conceptualised the research question, contributed to the data collection and data analyses, interpreted results, and drafted and edited the manuscript. $\mathrm{KB}, \mathrm{AT}$ and $\mathrm{BD}$ contributed to research question, study design, and interpretation of results. ER and VL contributed to the data analyses and interpretation of results and drafting of the manuscript. All authors critically commented on drafts of the manuscript and approved the final version.

\section{Funding}

This research was funded by an Australian Research Council Discovery Project (DP170100188). JV is supported by a Future Leader Fellowship from the National Heart Foundation of Australia (ID 101928). VL is supported by an Executive Dean's Postdoctoral Fellowship. The contents of this manuscript are the responsibility of the authors and do not reflect the views of the funding bodies.

\section{Availability of data and materials}

The dataset used and/or analysed during the current study are available from the corresponding author on reasonable request.

\section{Declarations}

\section{Ethics approval and consent to participate}

Ethics approval was obtained from the University Human Ethics Advisory Group (HEAG-H 94_2017). Informed consent was obtained from participants.

\section{Consent for publication}

Not applicable.

\section{Competing interests}

The authors declare that they have no competing interests.

\section{Author details}

${ }^{1}$ Institute for Physical Activity and Nutrition (IPAN), School of Exercise and Nutrition Sciences, Deakin University, Geelong, Australia. ${ }^{2}$ Burwood, Australia. ${ }^{3}$ Department of Public Health and Primary Care, Faculty of Medicine and Health Sciences, Ghent University, C. Heymanslaan 10, 9000 Ghent, Belgium. ${ }^{4}$ Movement and Nutrition for Health and Performance Research Group, Department of Movement and Sport Sciences, Faculty of Physical Education and Physical Therapy, Vrije Universiteit Brussel, Pleinlaan 2, 1050 Brussels, Belgium.

Received: 7 June 2021 Accepted: 15 September 2021

Published online: 09 October 2021

\section{References}

1. Biddle SJ, Ciaccioni S, Thomas G, Vergeer I. Physical activity and mental health in children and adolescents: an updated review of reviews and an analysis of causality. Psychol Sport Exerc. 2019;42:146-55.

2. Poitras VJ, Gray CE, Borghese MM, Carson V, Chaput JP, Janssen I, et al. Systematic review of the relationships between objectively measured physical activity and health indicators in school-aged children and youth. Appl Physiol Nutr Metab. 2016;41(6 Suppl 3):S197-239.

3. Donnelly JE, Hillman CH, Castelli D, Etnier JL, Lee S, Tomporowski P, et al. Physical activity, fitness, cognitive function, and academic achievement in children: a systematic review. Med Sci Sports Exerc. 2016;48(6):1197.

4. Aubert S, Barnes JD, Abdeta C, Abi Nader P, Adeniyi AF, Aguilar-Farias N, et al. Global matrix 3.0 physical activity report card grades for children and youth: results and analysis from 49 countries. J Phys Act Health. 2018;15(s2):S251-S73.

5. Troiano RP, Berrigan D, Dodd KW, Masse LC, Tilert T, McDowell M. Physical activity in the United States measured by accelerometer. Med Sci Sports Exerc. 2008;40(1):181-8.

6. Telama R. Tracking of physical activity from childhood to adulthood: a review. Obes Facts. 2009:3:187-95.

7. McCurdy LE, Winterbottom KE, Mehta SS, Roberts JR. Using nature and outdoor activity to improve children's health. Curr Probl Pediatr Adolesc Health Care. 2010;40(5):102-17.

8. Loukaitou-Sideris A, Sideris A. What brings children to the park? Analysis and measurement of the variables affecting children's use of parks. J Am Plan Assoc. 2010;76(1):89-107.

9. Adams J, Veitch J, Barnett L. Physical activity and fundamental motor skill performance of 5(-)10 year old children in three different playgrounds. Int J Environ Res Public Health. 2018;15(9):1896.

10. Cohen DA, Ashwood S, Scott M, Overton A, Evenson KR, Staten L, et al. Public parks and physical activity among adolescent girls. Pediatrics. 2006;118(5):1381-9.

11. Loukaitou-Sideris A, Sideris A. What brings children to the park? Analysis and measurement of the variables affecting children's use of parks. J Am Plan Assoc. 2009;76(1):89-107

12. Gladwell VF, Brown DK, Wood C, Sandercock GR, Barton JL. The great outdoors: how a green exercise environment can benefit all. Extrem Physiol Med. 2013:2(1):3.

13. Timperio A, Giles-Corti B, Crawford D, Andrianopoulos N, Ball K, Salmon $\mathrm{J}$, et al. Features of public open spaces and physical activity among children: findings from the CLAN study. Prev Med. 2008;47:514-8.

14. Evenson KR, Williamson S, Han B, McKenzie TL, Cohen DA. United States' neighborhood park use and physical activity over two years: the national study of neighborhood parks. Prev Med. 2019;123:117-22.

15. Joseph RP, Maddock JE. Observational Park-based physical activity studies: a systematic review of the literature. Prev Med. 2016;89:257-77.

16. Lindberg $M$, Schipperijn J. Active use of urban park facilities - expectations versus reality. Urban For Urban Green. 2015;14:909-18.

17. Lachowycz K, Jones AP, Page AS, Wheeler BW, Cooper AR. What can global positioning systems tell us about the contribution of different types of urban greenspace to children's physical activity? Health Place. 2012;18(3):586-94.

18. Floyd MF, Bocarro JN, Smith WR, Baran PK, Moore RC, Cosco NG, et al. Park-based physical activity among children and adolescents. Am J Prev Med. 2011:41(3):258-65. 
19. Veitch J, Carver A, Abbott G, Giles-Corti B, Timperio A, Salmon J. How active are people in metropolitan parks? An observational study of park visitation in Australia. BMC Public Health. 2015;15:610.

20. Spengler JO, Floyd MF, Maddock JE, Gobster PH, Suau LJ, Norman GJ. Correlates of park-based physical activity among children in diverse communities: results from an observational study in two cities. Am J Health Promot. 2011;25(5):e1-9.

21. Marquet O, Hipp JA, Alberico C, Huang JH, Fry D, Mazak E, et al. Park use preferences and physical activity among ethnic minority children in low-income neighborhoods in New York City. Urban For Urban Green. 2019;38:346-53.

22. Marquet O, Hipp JA, Alberico C, Huang JH, Mazak E, Fry D, et al. How does park use and physical activity differ between childhood and adolescence? A focus on gender and race-ethnicity. J Urban Health. 2019;96(5):692-702.

23. Reimers A, Schoeppe S, Demetriou Y, Knapp G. Physical activity and outdoor play of children in public playgrounds-do gender and social environment matter? Int J Environ Res Public Health. 2018;15(7):1356.

24. Flowers EP, Timperio A, Hesketh KD, Veitch J. Examining the features of parks that children visit during three stages of childhood. Int J Environ Res Public Health. 2019;16(9):1658.

25. Zhang R, Wulff H, Duan $Y$, Wagner P. Associations between the physical environment and park-based physical activity: a systematic review. J Sport Health Sci. 2018; 8(5):412-21.

26. Tappe KA, Glanz K, Sallis JF, Zhou C, Saelens BE. Children's physical activity and parents' perception of the neighborhood environment: neighborhood impact on kids study. Int J Behav Nutr Phys Act. 2013;10:39.

27. Besenyi GM, Kaczynski AT, Wilhelm Stanis SA, Bergstrom R, Oestman KB, Colabianchi N. Sex differences in the relationship between park proximity and features and child and youth physical activity. Child Youth Environ. 2016;26(1):56-84.

28. Gardsjord HS, Tveit MS, Nordh H. Promoting youth's physical activity through park design: linking theory and practice in a public health perspective. Landsc Res. 2014;39(1):70-81.

29. Kruger JS, Chawla L. "We know something someone doesn't know": children speak out on local conditions in Johannesburg. Environ Urban. 2002;14(2):85-96.

30. Veitch J, Salmon J, Ball K. Children's perceptions of the use of public open spaces for active free-play. Child Geogr. 2007;5(4):409-22.

31. Veitch J, Salmon J, Deforche B, Ghekiere A, Van Cauwenberg J, Bangay S, et al. Park attributes that encourage park visitation among adolescents: a conjoint analysis. Landsc Urban Plann. 2017;161:52-8.

32. Van Hecke L, Ghekiere A, Van Cauwenberg J, Veitch J, De Bourdeaudhuij I, Van Dyck D, et al. Park characteristics preferred for adolescent park visitation and physical activity: a choice-based conjoint analysis using manipulated photographs. Landsc Urban Plann. 2018;178:144-55.

33. Orme B. Getting started with conjoint analysis: strategies for product design and pricing research. Madison: Resarch Publishers; 2009.

34. Rivera E, Timperio A, Loh VH, Deforche B, Veitch J. Important park features for encouraging park visitation, physical activity and social interaction among adolescents: a conjoint analysis. Health Place. 2021;70:102617.

35. Rivera E, Timperio A, Venurs L, Deforche B, Veitch J. Critical factors influencing adolescents' active and social park use: a qualitative study using walk-along interviews. Urban For Urban Green. 2021;58:26948.
36. Veitch J, Flowers E, Ball K, Deforche B, Timperio A. Exploring children's views on important park features: a qualitative study using walk-along interviews. Int J Environ Res Public Health. 2020;7:4625.

37. Veitch J, Flowers E, Ball K, Deforche B, Timperio A. Designing parks for older adults: a qualitative study using walk-along interviews. Urban For Urban Green. 2020;54:126768.

38. Veitch J, Ball K, Flowers E, Deforche B, Timperio A. Children's ratings of park features that encourage park visitation, physical activity and social interaction. Urban For Urban Green. 2021:58:126963.

39. Australian Bureau of Statistics. Australian Bureau of Statistics, Socio-Economic Indexes for Areas (SEIFA) 2016, Australia. Canberra; 2016. Available from: www.abs.gov.au/ausstats/abs@.nsf/mf/2033.0.55.001.

40. Prochaska JJ, Sallis JF, Long B. A physical activity screening measure for use with adolescents in primary care. Arch Pediatr Adolesc Med. 2001;155(5):554-9.

41. Ridgers ND, Timperio A, Crawford D, Salmon J. Validity of a brief selfreport instrument for assessing compliance with physical activity guidelines amongst adolescents. J Sci Med Sport. 2012;15(2):136-41.

42. Mertens L, Van Cauwenberg J, Veitch J, Deforche B, Van Dyck D. Differences in park characteristic preferences for visitation and physical activity among adolescents: a latent class analysis. PLoS One. 2019;14(3):e0212920.

43. Orme B. Getting started with conjoint analysis: strategies for product design and pricing research. Manhattan Beach: Research Publishers; 2014

44. Sawtooth Software. ACBC Technical paper 2014. Available from: https:// sawtoothsoftware.com/resources/technical-papers/acbc-technicalpaper. Accessed 1 May 2021

45. Arora N, Allenby GM, Ginter JL. A hierarchical Bayes model of primary and secondary demand. Market Sci. 1998;17(1):29-44.

46. Cohen DA, Han B, Williamson S, Nagel C, McKenzie T, Evenson K, et al. Playground features and physical activity in U.S. neighborhood parks. Prev Med. 2020;131:105945.

47. Brussoni M, Gibbons R, Gray C, Ishikawa T, Sandseter EB, Bienenstock $A$, et al. What is the relationship between risky outdoor play and health in children? A systematic review. Int J Environ Res Public Health. 2015;12(6):6423-54.

48. Commission AS. AusPlay Focus: children's participation in organised physical activity outside of school hours: Australian Government; 2018. Available from: https://www.sportaus.gov.au/__data/assets/pdf_file/ 0004/675562/AusPlay_focus_Children_Participation_2.pdf

49. Veitch J, Salmon J, Ball K, Crawford D, Timperio A. Do features of public open spaces vary between urban and rural areas? Prev Med. 2013;56(2):107-11.

50. Aspinall PA, Thompson CW, Alves S, Sugiyama T, Brice R, Vickers A. Preference and relative importance for environmental attributes of neighbourhood open space in older people. Environ Plann B. 2010;37(6):1022-39.

\section{Publisher's Note}

Springer Nature remains neutral with regard to jurisdictional claims in published maps and institutional affiliations.

Ready to submit your research? Choose BMC and benefit from

- fast, convenient online submission

- thorough peer review by experienced researchers in your field

- rapid publication on acceptance

- support for research data, including large and complex data types

- gold Open Access which fosters wider collaboration and increased citations

- maximum visibility for your research: over 100M website views per year

At BMC, research is always in progress.

Learn more biomedcentral.com/submissions 